\title{
A 3-year follow-up study of inpatients with lower limb ulcers: evidence of an obesity paradox?
}

\author{
This article was published in the following Dove Press journal: \\ Journal of Multidisciplinary Healthcare \\ 8 August 2012 \\ Number of times this article has been viewed
}

\section{Michelle Miller' \\ Christopher Delaney² \\ Deanna Penna' \\ Lilian Liang' \\ Jolene Thomas' \\ Phillip Puckridge ${ }^{2}$ \\ James I Spark ${ }^{2}$}

'Department of Nutrition and Dietetics, Flinders University, Adelaide, Australia; ${ }^{2}$ Department of Vascular Surgery, Southern Adelaide Health Service, Adelaide, Australia
Correspondence: Michelle Miller Room 7EI 05.4 Flinders Medical Centre, Bedford Park, South Australia, Australia $\mathrm{Tel}+61882045328$

Fax +61882046406

Email michelle.miller@flinders.edu.au
Objectives: To determine whether body composition is related to long-term outcomes amongst vascular inpatients with lower limb ulcers.

Design: Prospective study with 3 years follow-up.

Materials and methods: Body mass index (BMI), fat, and fat-free mass were measured and associations with readmission to hospital (number, cause, length of stay) and all-cause mortality were explored.

Results: Thirty patients ( 22 men, 8 women) participated in the study. Ten patients $(33 \%)$ had a BMI $\geq 30 \mathrm{~kg} / \mathrm{m}^{2} .18 / 20(90 \%)$ patients with a BMI $<30 \mathrm{~kg} / \mathrm{m}^{2}$ and $9 / 10(90 \%)$ patients with a BMI $\geq 30 \mathrm{~kg} / \mathrm{m}^{2}$ were admitted to hospital in the 3 years of follow-up. Patients with a BMI $<30 \mathrm{~kg} / \mathrm{m}^{2}$ were admitted more frequently, earlier and for longer compared to those with BMI $\geq 30 \mathrm{~kg} / \mathrm{m}^{2}$ but these did not reach statistical significance. The 3 year mortality rate for patients with BMI $\geq 30 \mathrm{~kg} / \mathrm{m}^{2}$ was $20 \%(\mathrm{n}=2 / 10)$ compared to $70 \%(\mathrm{n}=14 / 20)$ with a BMI $<30 \mathrm{~kg} / \mathrm{m}^{2}, P=0.019$.

Conclusion: This preliminary study suggests that higher BMI may have a protective effect against mortality in vascular patients with lower limb ulcers. These findings contradict the universal acceptance that obesity leads to poor health outcomes. Further work is required to confirm these findings and explore some of the potential mechanisms for this effect.

Keywords: body mass index, fat mass, obesity, overweight, vascular, ulcers

\section{Introduction}

Overweight and obesity have recently been reported as modifiable risk factors for vascular disease. ${ }^{1}$ In contrast to this, there is evidence to suggest that being malnourished can impair wound healing and recovery from vascular surgery. ${ }^{2,3}$ This is a challenge for both clinicians and consumers as recommendations for a healthy body composition will conflict according to disease progression.

In established vascular disease, particularly the presence of critical limb ischemia, it is not uncommon for patients to present in a state of nutritional deficiency. These patients also have increased nutrient requirements for wound healing (eg, protein, zinc) $)^{4,5}$ and being malnourished has been shown to increase the incidence of septic complications. ${ }^{6}$ In established vascular disease it is still unknown what the ideal body composition might be but there has been some indication in the literature that it might be higher than the levels conventionally used as the ideal targets.

Two studies have examined the effect of body composition on mortality for vascular patients and reported that levels of fatness higher than conventionally used to describe healthy body composition might be beneficial. Davenport et $\mathrm{al}^{7}$ concluded that mild obesity (defined as body mass index [BMI] $>30 \mathrm{~kg} / \mathrm{m}^{2}$ and $\leq 35 \mathrm{~kg} / \mathrm{m}^{2}$ ) 
may be an advantage rather than a risk factor for adverse outcomes at 30 days postsurgery including morbidity and mortality. Similarly Nafiu et $a l^{8}$ concluded that patients within the conventional healthy BMI range were at greater risk of 30-day mortality postsurgery than those who were overweight or obese.

The rationale for the seemingly protective effect in vascular patients is not yet established but the protective effects are not unlike emerging evidence in studies of older adults whereby a higher BMI and avoiding weight loss has been demonstrated to be protective rather than detrimental. ${ }^{9-11}$ Similar findings have also been demonstrated in other groups of hospitalized patients. ${ }^{12-14}$ In contrast to previous studies that looked at short term outcomes associated with the protective effect of higher BMI, the purpose of this preliminary study was to determine whether this relationship persists longer term in vascular patients with lower limb ulcers. A particular emphasis is placed on outcomes of clinical relevance including hospital readmissions and all-cause mortality.

\section{Materials and methods}

\section{Patients}

All patients admitted to the Vascular Unit at the Repatriation General Hospital, Adelaide, South Australia, were screened for eligibility to participate in the study between August 2007 and November 2007. Patients were eligible if they were admitted for management of a lower limb ulcer of any etiology and excluded if they were palliative receiving comfort care, unable to fulfill the requirements of the study due to impaired cognitive function or receiving nutrition via enteral feeding or total parenteral nutrition. Patients with critical limb ischemia according to the TransAtlantic Inter-Society Consensus criteria were diagnosed with arterial ulcers. Venous ulcers were diagnosed with documented venous incompetence on duplex imaging, in the absence of established arterial disease as evidenced by ankle-brachial pressure indices $>0.9$. Neuropathic ulcers were diagnosed clinically in diabetic patients in the absence of venous or arterial disease.

The study was approved by the Repatriation General Hospital Research and Ethics Committee and the Southern Adelaide Clinical Human Research Committee. All patients provided written informed consent prior to commencement of data collection and were free to withdraw at any time.

\section{Measurements and procedures}

Baseline characteristics of participants including date of birth, gender, and medical history were obtained from medical records.
Body weight was measured in the morning with participants in light clothing and without shoes using calibrated chair scales $( \pm 0.1 \mathrm{~kg})$ (TI BWB-800C; Wedderburn, Malaga, WA, Australia). Knee height was measured as an estimate of standing height as the majority of patients were unable to assume the correct position for accurate measurement of standing height. Knee height $( \pm 0.1 \mathrm{~cm})$ was measured using a caliper with a fixed foot plate and an adjustable, sliding end plate with the lower right leg positioned at an angle of $90^{\circ}$ (Ross Laboratories, Columbus, OH). Standard validated equations for age and gender were used to estimate standing height. ${ }^{15}$ Weight and estimated standing height from knee height were used to calculate estimated BMI $\left(\mathrm{kg} / \mathrm{m}^{2}\right)$. Participants were classified as: (1) BMI $<30 \mathrm{~kg} / \mathrm{m}^{2}$, or (2) BMI $\geq 30 \mathrm{~kg} / \mathrm{m}^{2}$ (obese) for the purpose of this study. ${ }^{16}$

There is mounting evidence that percentage fat and fat-free mass are stronger predictors of health outcomes than body weight alone. ${ }^{17,18}$ Given the shortcoming of BMI reflecting only body size not body composition, measurement of fat and fat-free mass were included in this study. Fat and fat-free mass were determined to the nearest $0.1 \mathrm{~kg}$ using bioimpedance spectroscopy (BIS). BIS is a valid, portable, and relatively inexpensive method of estimating body composition. ${ }^{19}$ Impedance was measured in the morning with an empty bladder between the wrist and ankle using a tetrapolar electrode method as recommended by the manufacturer (SFB7 Multi-Frequency Analysis Version 5.2.4.0; ImpediMed, Eight Mile Plains, Australia). The patients were dressed in light clothing without shoes, socks, or jewelry and were instructed to lie supine with arms separated from the body and legs not touching each other. Measurements were taken on the right side consistent with standard protocol. ${ }^{20}$

Three year follow-up outcome data were obtained from medical records. Data included: time to first readmission (days), number of readmissions, cause of readmission (cardiovascular disease, respiratory, amputation, infection, other) total days in hospital from readmissions (days), allcause mortality (alive/deceased) and days to death.

All data was analyzed using the SPSS statistical package (PASW version 18.0; SPSS Inc, Chicago, IL). Data was expressed as median (range) or $\mathrm{n}(\%)$. Mann-Whitney $U$ tests were performed to determine associations between fat mass and fat-free mass according to whether patients were readmitted or died in the subsequent 3 years. Mann-Whitney $U$ tests were also performed to determine whether cause of readmission, number of readmissions, and total days of hospitalization in the subsequent 3 years were associated with BMI classification. Chi-square analyses were performed to 
determine whether BMI classification was associated with readmission to hospital or death in the subsequent 3 years. Kaplan-Meier survival analyses with log rank (Mantel-Cox) tests were performed to determine whether BMI classification was associated with days to first readmission and days to death. Hierarchical cox regression was performed to determine the effect of BMI on mortality independent of ulcer etiology. Findings were considered significant at the level of $P<0.05$.

\section{Results}

Table 1 represents the baseline characteristics of the 30 patients included in this study. Patients were mostly elderly (median age 78 years, range 40-91 years) and there was no significant difference in age between those with BMI $<30 \mathrm{~kg} / \mathrm{m}^{2}$ and $\mathrm{BMI} \geq 30 \mathrm{~kg} / \mathrm{m}^{2}$. Similarly there was no significant difference in sex between those with BMI $<30 \mathrm{~kg} / \mathrm{m}^{2}$ and BMI $\geq 30 \mathrm{~kg} / \mathrm{m}^{2}$, with the majority being male $(\mathrm{n}=22 / 30$, $73 \%$ ). Diabetes, heart disease, hyperlipidemia, and hypertension were common as was obesity. No patients were underweight $\left(\mathrm{BMI}<18.5 \mathrm{~kg} / \mathrm{m}^{2}\right)$. The etiology of the lower limb ulcers included arterial $\left(\mathrm{n}=12 / 20 \mathrm{BMI}<30 \mathrm{~kg} / \mathrm{m}^{2} ; 2 / 10\right.$ $\left.\mathrm{BMI} \geq 30 \mathrm{~kg} / \mathrm{m}^{2}\right)$, neuropathic $\left(\mathrm{n}=4 / 20 \mathrm{BMI}<30 \mathrm{~kg} / \mathrm{m}^{2}\right.$; $7 / 10 \mathrm{BMI} \geq 30 \mathrm{~kg} / \mathrm{m}^{2}$ ), and others (venous ulcers, pressure ulcers, squamous cell carcinoma each $n=1,2$ unknown).

Table 2 reports the outcomes at 3 years for the 30 patients included in this study according to BMI classification. 18/20 $(90 \%)$ patients with a BMI $<30 \mathrm{~kg} / \mathrm{m}^{2}$ and $9 / 10(90 \%)$ patients with a BMI $\geq 30 \mathrm{~kg} / \mathrm{m}^{2}$ were admitted to a hospital in the 3 years of follow-up. There were a total of 154 admissions (60 vascular, 38 general medicine, 25 respiratory, 14 cardiovascular, 6 orthopedics, 6 gastroenterology, and 5 renal);

Table I Baseline descriptive characteristics of 30 patients admitted to the vascular unit with lower limb ulcers between August and November 2007

\begin{tabular}{|c|c|c|}
\hline Characteristic & $\begin{array}{l}\text { BMI }<30 \mathrm{~kg} / \mathrm{m}^{2} \\
(\mathrm{n}=20)\end{array}$ & $\begin{array}{l}\mathrm{BMI} \geq 30 \mathrm{~kg} / \mathrm{m}^{2} \\
(\mathrm{n}=\mathrm{I0})\end{array}$ \\
\hline Males & $15(75 \%)$ & 7 (70\%) \\
\hline Age $<60$ years & $4(20 \%)$ & $2(20 \%)$ \\
\hline Diabetes mellitus & II (55\%) & $8(80 \%)$ \\
\hline Hypertension & II (55\%) & $5(50 \%)$ \\
\hline Ischemic heart disease & $8(40 \%)$ & $5(50 \%)$ \\
\hline Hyperlipidemia & 14 (70\%) & $8(80 \%)$ \\
\hline Weight, kg & $76.5(44.2,92.6)$ & $105.8(87.9,129.6)$ \\
\hline Fat mass, kg & $25.5(10.1,36.9)$ & $44.1(22.5,49.9)^{\ddagger}$ \\
\hline Fat mass, \% & $67.0(54.2,85.4)$ & $55.9(49.7,82.6)$ \\
\hline Fat-free mass, kg & $46.1(33.1,67.1)$ & $57.7(43.8,107.1)^{\dagger}$ \\
\hline Fat-free mass, \% & $33.0(14.6,45.8)$ & $44.1(17.4,50.2)$ \\
\hline
\end{tabular}

Notes: Data are reported as $\mathrm{n}(\%)$ or median (range) and statistical analyses performed using Chi-square and Mann-Whitney $U$. ${ }^{\dagger} P<0.05$; $¥ P<0.01$. Abbreviation: $\mathrm{BMI}$, body mass index.
Table 2 Outcome data for 30 patients admitted to the vascular unit with lower limb ulcers between August and November 2007

\begin{tabular}{|c|c|c|}
\hline Characteristic & $\begin{array}{l}\text { BMI }<30 \mathrm{~kg} / \mathrm{m}^{2} \\
(\mathrm{n}=20)\end{array}$ & $\begin{array}{l}\mathrm{BMI} \geq 30 \mathrm{~kg} / \mathrm{m}^{2} \\
(\mathrm{n}=10)\end{array}$ \\
\hline \multicolumn{3}{|l|}{ Readmissions } \\
\hline Number of readmissions & $5(0,15)$ & $4(0,18)$ \\
\hline $\begin{array}{l}\text { Total days inpatient from } \\
\text { all readmissions }\end{array}$ & $52(1,263)$ & $4 I(9,228)$ \\
\hline Days to first readmission & $66(5,8 \mid 2)$ & $72(24,302)$ \\
\hline \multicolumn{3}{|l|}{ Readmission events } \\
\hline Cardiovascular disease & $8 / 102(8 \%)$ & $3 / 52(6 \%)$ \\
\hline Respiratory & $15 / 102$ (15\%) & $8 / 52(15 \%)$ \\
\hline Infection & $18 / 102$ (18\%) & $23 / 52(44 \%)$ \\
\hline Any amputation & $10 / 102(10 \%)$ & $4 / 52(8 \%)$ \\
\hline Other & $51 / / 02(50 \%)$ & $14 / 52(27 \%)$ \\
\hline \multicolumn{3}{|l|}{ All-cause mortality } \\
\hline Deceased & I4/20 (70\%) & $2 / 10(20 \%)^{\dagger}$ \\
\hline Days to death & 669 (2I, I095) & $25 \mathrm{I}(73,429)$ \\
\hline
\end{tabular}

Notes: Data presented as $\mathrm{n}(\%)$ or median (range) and statistical analyses performed using Chi-square and Mann-Whitney $U .{ }^{\dagger} P<0.05$

Abbreviation: BMI, body mass index.

102 for those with BMI $<30 \mathrm{~kg} / \mathrm{m}^{2}$ and 52 for those with $\mathrm{BMI} \geq 30 \mathrm{~kg} / \mathrm{m}^{2}$. Patients with a BMI $<30 \mathrm{~kg} / \mathrm{m}^{2}$ were admitted more frequently, earlier, and for longer compared to those with $\mathrm{BMI} \geq 30 \mathrm{~kg} / \mathrm{m}^{2}$. However, these did not reach statistical significance. Readmissions for cardiovascular disease, respiratory disease, or amputation (minor/major) of the lower limb were evenly distributed between both BMI classifications. Kaplan-Meier survival analysis (Figure 1) demonstrated that there was no difference in time to

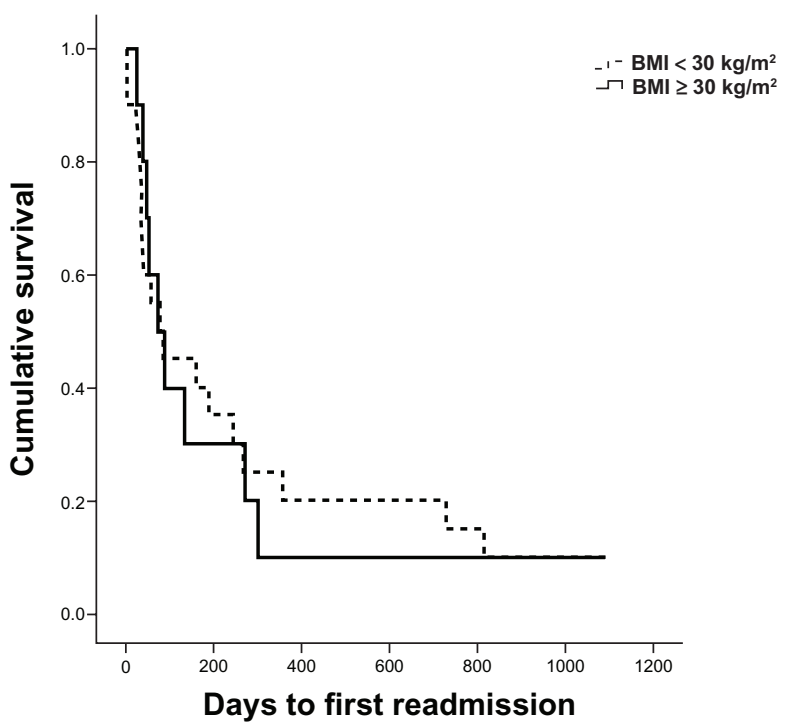

Figure I Survival curve for number of days to first readmission according to BMI. Notes: Survival curve for number of days to first readmission according to BMI for 30 patients admitted to the vascular unit with lower limb ulcers between August and November 2007 and followed up for 3 years. $P=0.542$ according to Kaplan-Meier log rank test.

Abbreviation: BMI, body mass index. 
hospitalization for those with a BMI $\geq 30 \mathrm{~kg} / \mathrm{m}^{2}$ compared to those with BMI $<30 \mathrm{~kg} / \mathrm{m}^{2}(P=0.498)$.

Sixteen $(53 \%)$ patients died during the 3 year follow-up (4 respiratory, 2 cardiovascular, 10 unknown). Two (20\%) patients with a BMI $\geq 30 \mathrm{~kg} / \mathrm{m}^{2}$ died while $14(70 \%)$ patients with a BMI $<30 \mathrm{~kg} / \mathrm{m}^{2}$ died $(P=0.019)$. Kaplan-Meier survival analysis (Figure 2 ) demonstrated that those patients with a BMI $\geq 30 \mathrm{~kg} / \mathrm{m}^{2}$ survived longer than those with a $\mathrm{BMI}<30 \mathrm{~kg} / \mathrm{m}^{2}(P=0.027)$. Hierarchical cox regression determined that those patients with BMI $<30 \mathrm{~kg} / \mathrm{m}^{2}$ were 4.6 times more likely to die than those with BMI $\geq 30 \mathrm{~kg} / \mathrm{m}^{2}$ (95\% confidence interval [CI]: $1.04-20.4 ; P=0.04$ ). When ulcer etiology was entered into the model those with $\mathrm{BMI}<30 \mathrm{~kg} / \mathrm{m}^{2}$ were 4.1 times more likely to die than those with BMI $\geq 30 \mathrm{~kg} / \mathrm{m}^{2}$ (95\% CI: 0.89-19.19; $\left.P=0.07\right)$ and those with arterial ulcers were no more likely to die than those with ulcers of other etiology (hazard ratio, 1.4; 95\% CI: $0.48-3.90 ; P=0.57)$.

Fat and fat-free mass according to whether patients were admitted to a hospital or had died in the subsequent 3 years are reported in Table 3. Median fat mass for those that died in the subsequent 3 years follow-up was significantly lower compared to those that survived the 3 years follow-up $(P=0.033)$. There was no significant relationship found between fat mass and readmission to hospital, or fat-free mass and either mortality or readmission to a hospital. When explored as percent fat and fat-free mass there were no significant differences identified.

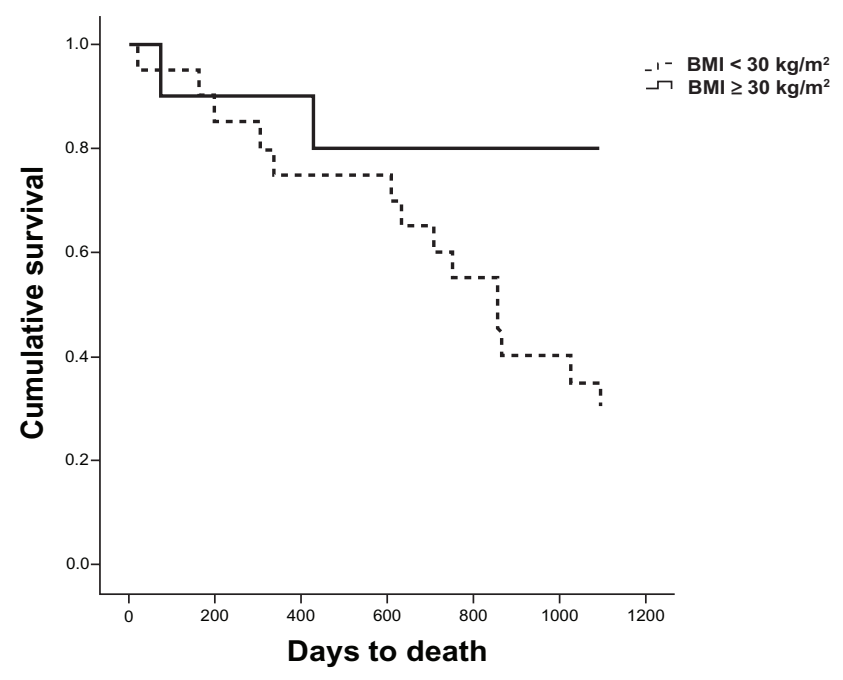

Figure 2 Survival curve for number of days to death according to BMI.

Notes: Survival curve for number of days to death according to BMI for 30 patients admitted to the vascular unit with lower limb ulcers between August and November 2007 and followed up for three years. $P=0.027$ according to Kaplan-Meier log rank test.

Abbreviation: BMI, body mass index.

\section{Discussion}

The findings of this small study suggest that obesity is common for patients with lower limb ulcers and that a higher weight for height may be protective in terms of mortality. These findings challenge evidence that poor outcomes are routinely associated with higher $\mathrm{BMI}^{16}$ and provides direction for further research to evaluate whether strategies for weight maintenance, regardless of baseline weight, improves health outcomes.

The concept that having a BMI above the ideal weight range seems to have a protective effect for vascular patients was supported with a trend suggesting that those with a BMI $<30 \mathrm{~kg} / \mathrm{m}^{2}$ were also readmitted to a hospital sooner and stayed longer than those classified as obese (BMI $\geq 30 \mathrm{~kg} / \mathrm{m}^{2}$ ).

While inconsistent with evidence suggesting higher body weight for height is associated with poor outcomes, ${ }^{16}$ the findings of the present study do appear to be consistent with two previous studies exploring the ideal BMI range for vascular patients. ${ }^{7,8}$ Davenport et $\mathrm{al}^{7}$ found in a sample of 7543 vascular patients undergoing a variety of surgical procedures that BMI between $30-35 \mathrm{~kg} / \mathrm{m}^{2}$ was protective against perioperative 30 day mortality. Similarly, Nafiu et $\mathrm{al}^{8}$ reported poorest outcomes amongst vascular patients that were underweight or in the desirable BMI range compared to those classified as overweight or obese. These outcomes included perioperative 30 day mortality and trends were also evident for a range of postoperative complications. For both studies the mean age of participants was $>60$ years, perhaps allowing some synergies to be drawn from longstanding evidence in geriatrics and inpatient populations that higher BMI is protective. ${ }^{16}$

Increasingly, there is evidence amongst older adults that a higher BMI might be advantageous. While the mechanism underlying this protective effect is not clearly understood, the 'obesity paradox' as it has been reported, is clearly a valid concept with many studies reporting a significant survival benefit for older adults. ${ }^{21-23}$ One proposed mechanism for the protective effects illustrated in the geriatric literature is the reduction in oxidative stress and inflammation associated with maintaining a higher body weight and avoiding weight loss and sarcopenia. ${ }^{22}$ Lower fat-free mass has been linked to reduced antioxidant capacity and poor outcomes. ${ }^{24}$ The additional energy reserves assist in retaining lean body mass and hence prevention of malnutrition may also be responsible for the protective effects observed. Adiposity in the latter years is also understood to assist in maintaining bone mineral density and can provide protection against fall-related fractures, an event known to be associated with a high mortality rate. ${ }^{22}$ Which, if any, of these mechanisms 
Table 3 Outcome data at 3 years for 30 patients admitted to the vascular unit with lower limb ulcers between August and November 2007 according to fat $(\mathrm{kg}, \%)$ and fat-free mass $(\mathrm{kg}, \%)$ as measured by bioelectrical impedance analysis

\begin{tabular}{lllll}
\hline & Fat mass, $\mathbf{~ k g}$ & Fat mass, $\%$ & Fat-free mass, kg & Fat-free mass, \% \\
\hline $\begin{array}{l}\text { Readmitted to hospital } \\
\text { Yes }\end{array}$ & $28.5(10.1,49.9)$ & $62.1(49.7,85.4)$ & $56.2(33.1,107.1)$ & $37.7(14.6,50.2)$ \\
$\quad$ No & $32.1(21.0,43.2)$ & $62.3(55.9,68.7)$ & $50.5(46.1,54.8)$ & $37.7(31.3,44.1)$ \\
Mortality & & & & \\
$\quad$ Deceased & $25.5(10.1,48.1)^{\dagger}$ & $67.0(55.8,82.6)$ & $46.1(33.1,107.1)$ & $33.0(17.4,44.3)$ \\
$\quad$ Alive & $40.4(11.1,49.9)$ & $59.1(49.7,85.4)$ & $57.0(36.5,75.5)$ & $40.8(14.6,50.2)$ \\
\hline
\end{tabular}

Notes: Data presented as median (range) and statistical analyses performed using Mann-Whitney $U$ for fat or fat-free mass and readmission to hospital or death. ${ }^{\dagger} P<0.05$.

are responsible for the findings of the present study cannot be determined but highlights that the question is worthy of further exploration. So too is the evaluation of energy needs and expenditures associated with ulcers of different size and etiology which would aid calculation of nutritional requirements for specific patient groups, potentially preventing weight loss and malnutrition and improving outcomes.

There is an argument that increased survival at any cost may not be the preference of patients. Some studies have shown that there is an increased risk of other complications and delayed wound healing in patients that are overweight or obese ${ }^{25}$ and hence quality of life, not only quantity of life, needs to be considered. A discrete choice experiment to elicit the views and preferences of vascular patients about alternative health states would be helpful to inform this discussion.

Of interest in this study was the lack of effect observed for a relationship between fat mass and readmission to hospital and fat-free mass and either mortality or readmission to hospital. While there was a trend for those with lower fat mass to be more likely to be readmitted to hospital and for those with a lower fat-free mass to be deceased, the differences did not achieve statistical significance and were not consistent when examining percent fat and fat-free mass. In contrast, and against what might be expected, those participants with higher fat-free mass seemed to be more likely to be readmitted to hospital however statistical significance again was not achieved so these findings should be interpreted with caution as they might simply be a chance trend that does not persist with a larger sample size. There are no clear indications why this trend would in fact be true.

It is important to acknowledge that the present study did not allow for classifications across the range of obesity classes due to the small sample size. Caution is therefore necessary in extrapolating the findings to those with a BMI $>40 \mathrm{~kg} / \mathrm{m}^{2}$ where there is some evidence to suggest that poorer health outcomes once again become concerning. ${ }^{7,8}$ The small sample size and associated risk of type 2 error may likely have contributed to the inability to demonstrate statistically significant findings for the range of outcomes explored. The study could also have been strengthened with a sample size sufficient to undertake multivariate analyses to determine the strength of BMI, fat mass, and fat-free mass in predicting mortality and hospital admissions after controlling for a range of potential confounders (including concomitant disease, medication, and mobility). In the present study it was clear that there was a difference in the proportion of participants with an arterial ulcer between the BMI classifications, an important consideration for multivariate analyses in the future as it is recognized that patients with critical limb ischemia have higher mortality. It would also be of interest for future studies with sufficient samples to generate survival curves by ulcer type to help illustrate the above. Alternative measures of body size and composition may also be warranted for future studies. BMI does not differentiate between central or peripherally stored weight which may influence outcomes. ${ }^{16}$ Waist and hip circumference may be more useful for examining differences in position of stored weight and should be considered for future studies. ${ }^{16}$ Similarly, there are arguments that BIS may not provide a valid estimate of fat and fat-free mass and that dual energy X-ray absorptiometry would be more appropriate. ${ }^{26}$ While dual energy X-ray absorptiometry is clearly a more valid technique, it is far less accessible and more expensive than BIS and hence its application for clinical purposes is limited. ${ }^{27,28}$ Despite these limitations, the findings of the present study do extend the current body of evidence by demonstrating preliminary evidence to suggest that the protective effect of a higher BMI may extend beyond the 30 days previously reported in surgical patients over a longer duration in vascular patients with lower limb ulcers.

Given these findings, recommendations regarding weight management for vascular patients may need to be revised in the future; what is recommended for the general population may not be appropriate for vascular patients. Future investigations should be conducted to confirm these preliminary 
findings and further study the long-term outcomes for these patients and what mechanisms are responsible for this potentially protective effect.

\section{Acknowledgments}

The authors wish to acknowledge the participation of the patients without whom this study would not have been possible.

\section{Disclosure}

This research received no specific grant from any funding agency in the public, commercial or not-for-profit sectors. The authors report no conflicts of interest in this work.

\section{References}

1. Rao GH, Thethi I, Fareed J. Vascular disease: obesity and excess weight as modulators of risk. Expert Rev Cardiovasc Ther. 2011;9(4): 525-534.

2. Thompson C, Fuhrman M. Nutrients and wound healing: still searching for the magic bullet. Nutr Clin Pract. 2005;20(3):331-347.

3. Williams JZ, Barbul A. Nutrition and wound healing. Surg Clin North Am. 2003;83(3):571-596.

4. Breslow RA, Hallfrisch J, Guy DG, Crawley B, Goldberg AP. The importance of dietary protein in healing pressure ulcers. J Am Geriatr Soc. 1993;41(4):357-362.

5. Greaves MW, Skillen AW. Effects of long-continued ingestion of zinc sulphate in patients with venous leg ulceration. Lancet. 1970;2(7679): 889-891.

6. Durkin MT, Mercer KG, McNulty MF, et al. Contribution of malnutrition to postoperative morbidity in vascular surgical patients. Br J Surg. 1999;86(5):690-711.

7. Davenport DL, Xenos ES, Hosokawa P, Radford J, Henderson WG, Endean ED. The influence of body mass index obesity status on vascular surgery 30-day morbidity and mortality. J Vasc Surg. 2009;49(1): $140-147$.

8. Nafiu OO, Kheterpal S, Moulding R, et al. The association of body mass index to postoperative outcomes in elderly vascular surgery patients: a reverse J-curve phenomenon. Anesth Analg. 2011;112(1): 23-29.

9. Beck AM, Ovesen L. At which body mass index and degree of weight loss should hospitalized elderly patients be considered at nutritional risk? Clin Nutr. 1998;17(5):195-198.

10. Bannerman E, Miller MD, Daniels LA, et al. Anthropometric indices predict physical function and mobility in older Australians: the Australian Longitudinal Study of Ageing. Public Health Nutr. 2002;5(5):655-662.

11. Newman AB, Yanez D, Harris T, et al. Weight change in old age and its association with mortality. J Am Geriatr Soc. 2001;49(10): 1309-1318.
12. Landi F, Onder G, Gambassi G, Pedone C, Carbonin P, Bernabei R. Body mass index and mortality among hospitalized patients. Arch Intern Med. 2000;160(17):2641-2644.

13. Hall JA, French TK, Rasmusson KD, et al. The paradox of obesity in patients with heart failure. J Am Acad Nurse Pract. 2005;17(12): $542-546$.

14. Vigder C, Ben Israel Y, Meisel SR, Kaykov E, Gottlieb S, Shotan A. Management and 1 year outcome of oldest-old hospitalized heart failure patients: a subacute geriatric hospital survey. Isr Med Assoc J. 2010;12(8):483-488.

15. Chumlea WC, Guo S. Equations for predicting stature in white and black elderly individuals. J Gerontol. 1992;47(6):M197-M203.

16. Dietitians Association of Australia. Best Practice Guidelines for the Treatment of Overweight and Obesity in Adults. Canberra, Australia: Dietitians Association of Australia; 2005.

17. Segal KR, Dunaif A, Gutin B, Albu J, Nyman A, Pi-Sunyer FX. Body composition, not body weight, is related to cardiovascular disease risk factors and sex hormone levels in men. J Clin Invest. 1987;80(4): 1050-1055.

18. VanItallie TB, Yang MU, Heymsfield SB, Funk RC, Boileau RA. Height-normalised indices of the body's fat-free mass and fat mass: potentially useful indicators of nutritional status. Am J Clin Nutr. 1990;52(6):953-959.

19. Tengvall M, Ellegård L, Malmros V, Bosaeus N, Lissner L, Bosaeus I. Body composition in the elderly: reference values and bioelectrical impedance spectroscopy to predict total body skeletal muscle mass. Clin Nutr. 2009;28(1):52-58.

20. Heyward VH. Practical body composition assessment for children, adults, and older adults. Int J Sport Nutr. 1998;8(3):285-307.

21. Chapman IM. Obesity paradox during aging. Interdiscip Top Gerontol. 2010;37:20-36.

22. Oreopoulos A, Kalantar-Zadeh K, Sharma AM, Fonarow GC. The obesity paradox in the elderly: potential mechanisms and clinical implications. Clin Geriatr Med. 2009;25(4):643-659.

23. Trullàs JC, Formiga F, Montero M, et al. Paradox of obesity in heart failure: results from the Spanish RICA Registry. Med Clin (Barc). 2011;137(15):671-677.

24. Spark JI, Robinson JM, Gallavin L, et al. Patients with chronic critical limb ischaemia have reduced total antioxidant capacity and impaired nutritional status. Eur J Vasc Endovasc Surg. 2002;24(6):535-539.

25. Fasol R, Schindler M, Schumacher B, et al. The influence of obesity on perioperative morbidity: retrospective study of 502 aortocoronary bypass operations. Thorac Cardiovasc Surg. 1992;40(3):126-129.

26. Bussolotto M, Ceccon A, Sergi G, Giantin V, Benincà P, Enzi G. Assessment of body composition in elderly: accuracy of bioelectrical impedance analysis. Gerontology. 1999;45(1):39-43.

27. Li C, Ford ES, Zhao G, Balluz LS, Giles WH. Estimates of body composition with dual-energy X-ray absorptiometry in adults. Am J Clin Nutr. 2009;90(6):1457-1465.

28. Williams JE, Wells JC, Wilson CM, Haroun D, Lucas A, Fewtrell MS. Evaluation of Lunar Prodigy dual-energy X-ray absorptiometry for assessing body composition in healthy persons and patients by comparison with the criterion 4-component model. Am J Clin Nutr. 2006;83(5):1047-1054.

\section{Publish your work in this journal}

The Journal of Multidisciplinary Healthcare is an international, peerreviewed open-access journal that aims to represent and publish research in healthcare areas delivered by practitioners of different disciplines. This includes studies and reviews conducted by multidisciplinary teams as well as research which evaluates the results or conduct of such teams or

healthcare processes in general. The journal covers a wide range of areas and welcomes submission from practitioners at all levels, from all over the world. The manuscript management system is completely online and includes a very quick and fair peer-review system. Visit http://www.dovepress.com/testimonials.php to read real quotes from published authors. 